\title{
Article
}

\section{The Growth Behavior of Amorphous Hydrogenated Carbon a-C:H Layers on Industrial Polycarbonates-A Weak Interlayer and a Distinct Dehydrogenation Zone}

\author{
Torben Schlebrowski ${ }^{1, * \mathbb{D}}$, Melanie Fritz ${ }^{1} \mathbb{D}$, Lucas Beucher ${ }^{1}$, Yongxin Wang ${ }^{2} \mathbb{D}$, Stefan Wehner ${ }^{1} \mathbb{D}$ \\ and Christian B. Fischer $1,3, * \mathbb{D}$ \\ 1 Department of Physics, University Koblenz-Landau, 56070 Koblenz, Germany; \\ melfritz@uni-koblenz.de (M.F.); lucasbeucher@uni-koblenz.de (L.B.); wehner@uni-koblenz.de (S.W.) \\ 2 Key Laboratory of Marine New Materials and Related Technology, Zhejiang Key Laboratory of Marine \\ Materials and Protection Technology, Ningbo Institute of Materials Technology and Engineering, \\ Chinese Academy of Sciences, Ningbo 315201, China; yxwang@nimte.ac.cn \\ 3 Materials Science, Energy and Nano-Engineering Department, Mohammed VI Polytechnic University, \\ Ben Guerir 43150, Morocco \\ * Correspondence: schlebrowski@uni-koblenz.de (T.S.); chrbfischer@uni-koblenz.de (C.B.F.); \\ Tel.: +49-261-287-2365 (T.S.); +49-261-287-2345 (C.B.F.)
}

check for updates

Citation: Schlebrowski, T.; Fritz, M.; Beucher, L.; Wang, Y.; Wehner, S.; Fischer, C.B. The Growth Behavior of Amorphous Hydrogenated Carbon a-C:H Layers on Industrial Polycarbonates-A Weak Interlayer and a Distinct Dehydrogenation Zone. C 2021, 7, 59. https:/ / doi.org/ $10.3390 /$ c7030059

Academic Editor: Gil Goncalves

Received: 29 June 2021

Accepted: 26 July 2021

Published: 29 July 2021

Publisher's Note: MDPI stays neutral with regard to jurisdictional claims in published maps and institutional affiliations.

Copyright: (c) 2021 by the authors. Licensee MDPI, Basel, Switzerland. This article is an open access article distributed under the terms and conditions of the Creative Commons Attribution (CC BY) license (https:// creativecommons.org/licenses/by/ $4.0 /)$.

\begin{abstract}
Polycarbonate (PC) is a material that is used in many areas: automotive, aerospace engineering and data storage industries. Its hardness is of particular importance, but some applications are affected by its low wettability or scratch susceptibility. This can be changed either by blending with other polymers, or by surface modifications, such as the application of an amorphous hydrogenated carbon layer (a-C:H). In this study, individual a-C:H layers of different thicknesses (10-2000 nm) were deposited on PC by RF PECVD. Both the layer morphology with AFM and SEM and the bonding states of the carbon on the surface with synchrotron-assisted XPS and NEXAFS were studied. The aim was to investigate the coatability of PC and the stability of the a-C:H. Special attention was paid to the interlayer region from 0 to $100 \mathrm{~nm}$, since this is responsible for the layer to base material bonding, and to the zone of dehydrogenation (from about $1000 \mathrm{~nm}$ ), since this changes the surface composition considerably. For PC, the interlayer was relatively small with a thickness of only $20 \mathrm{~nm}$. Additionally, a correlation was found between the evolving grain structure and the development of the C-H peak according to NEXAFS C K-edge measurements.
\end{abstract}

Keywords: a-C:H grain development; PECVD plasma coating; gradual film deposition; synchrotron radiation; a-C:H-polymer interlayer; surface morphology

\section{Introduction}

Polycarbonate (PC) is a transparent polymer and is used in many technical applications due to its advantageous mechanical properties and its processability. For example, it is utilized not only in aerospace and automotive engineering, but also in the construction industry and optical lenses [1-3]. However, PC itself has disadvantages, such as high hydrophobicity and notch sensitivity. These properties can be modified-for example, by blending with other thermoplastic polymers [2]. Another way to influence these properties is to deposit a (thin) layer of amorphous carbon (a-C) or amorphous hydrogenated carbon (a-C:H) on its surface [4-8]. These carbon layers consist of a network of $\pi-\mathrm{sp}^{2}, \sigma-\mathrm{sp}^{2}$ and $\mathrm{sp}^{3}$ hybridized carbon atoms in which the hydrogen is embedded $[6,9,10]$.

The wettability of these layers is influenced by the morphology [11,12] and the chemical bonds on the surface $[13,14]$, as well as by the carbon bonds present on the surface $\left(\mathrm{sp}^{2}\right.$ or $\mathrm{sp}^{3}$ hybridized) [15-18]. Coatings with a-C:H are suitable for altering the wettability of the surface sustainably $[5,8,19,20]$. The ratio of the carbon hybridization states can be influenced by the plasma parameters during the coating process, the gas used, the amount 
of hydrogen $[6,9,17,21,22]$ and the coating thickness itself $[19,20,23]$. This carbon state ratio also affects the scratch resistance of the coating obtained. If the $\mathrm{sp}^{2} / \mathrm{sp}^{3}$ ratio is very low, a very hard, diamond-like coating is obtained (high hardness, chemical inertness and high electrical resistance) [21]. If the proportion of $\mathrm{sp}^{3}$ bonds on the surface is reduced in favor of the $\mathrm{sp}^{2}$ bonds, the layer has graphite-like properties, such as improved electrical conductivity on the surface of the coated material [21].

Various techniques can be used to deposit such a-C:H layers: e.g., ion beam deposition, magnetron sputtering and radio frequency plasma enhanced chemical vapor deposition (RF-PECVD) $[6,21,23,24]$. The latter was used in this study to deposit coatings on PC, as its low process temperatures make it ideal for coating non-conductive polymers [21,25].

However, before such a layer can be used to specifically influence the properties of such a material, the basic coatability must first be investigated. The important question is whether an interlayer forms and how pronounced it is. The interlayer is a mixed phase of the base material and the a-C:H layer deposited by the plasma. During the plasma process, the species which are generated interact with the substrate via impinging and surface reorganization [26]; additionally, material from the substrate may be eroded and incorporated into the forming layer. These processes lead to better crosslinking of the two systems, and the more pronounced the interlayer is, the better the adhesion of the a-C:H layer [24]. Polyoxymethylene (POM), for example, does not form a measurable interlayer; the layer can simply be detached [27]. High-density polyethylene (HDPE), on the other hand, has a very pronounced interlayer that is $40 \mathrm{~nm}$ thick and has very good connectivity to the polymer $[8,28]$. As soon as the plasma has hardly any influence on the base material, the interlayer formation is completed and regular layer growth begins. Furthermore, it must be determined whether the so-called dehydrogenation of the layers takes place as soon as a certain layer thickness is exceeded [5,8,27-29]. Here, hydrogen is released from the a-C:H layer, whereby the proportion of $\mathrm{sp}^{2}$-bonded carbon increased at the expense of the $\mathrm{sp}^{3}$ bonds, which ultimately influenced the layers' properties. The layer stability itself and the detection of non-stable layer thicknesses must also be checked in advance.

In the current study, these investigations were carried out for the transparent polymer PC. By RF-PECVD technique and acetylene plasma, a-C:H layers of various thicknesses $(0-2000 \mathrm{~nm})$ were deposited and examined. Special attention was paid to the a-C:H layer from 10 to $50 \mathrm{~nm}$. Fine subdivisions were used here, since the interlayer manifests itself in this range. The layer stability was investigated ex situ by scanning electron microscopy (SEM). A more microscopic view of the surface morphology was possible with atomic force microscopy (AFM). Finally, the carbon bond states at the film's surface were analyzed by X-ray photoelectron spectroscopy (XPS) and near-edge X-ray absorption fine structure (NEXAFS).

\section{Materials and Methods}

\subsection{Sample Preparation}

PC material was supplied as $2 \mathrm{~mm}$ thick sheets by Goodfellow (Bad Nauheim, Germany). It was of industrial quality. Samples with $\varnothing 10 \mathrm{~mm}$ were stamped out and subsequently cleaned with isopropanol in an ultrasonic bath. For the coating, they were mounted on a vacuum-compatible aluminum holder and placed in a vacuum chamber at a distance of $275 \mathrm{~mm}$ in front of the plasma source. The high frequency plasma source used was a Copra DN 400 (CCR GmbH, Troisdorf, Germany) operating at 13.65 MHz [24]. The coating of the sample surface was processed in two separate plasma processes: first, the samples were cleaned and activated for $10 \mathrm{~min}$ in oxygen plasma. Second, an acetylene plasma was used for the a-C:H coating. The process duration depended on the desired coating thickness [5,8,27]. The processes can be read about in detail elsewhere [23]. During the plasma processes, the sample temperature never exceeded $40{ }^{\circ} \mathrm{C}$ [25]. Different layer thicknesses from $0\left(\mathrm{O}_{2}\right.$-treated PC sample) to $2000 \mathrm{~nm}$ were realized this way. The thickness intervals were variable and depended on the thickness range investigated: $0-100 \mathrm{~nm}$ in $10 \mathrm{~nm}$ steps in the interlayer region, $100-1000 \mathrm{~nm}$ in $100 \mathrm{~nm}$ steps and 1000-2000 nm in 
$250 \mathrm{~nm}$ steps. The coating rates were, apart from small variations in initial growth, constant over time and were about $10 \mathrm{~nm} / \mathrm{min}$ [23]. In order to check the coating thicknesses subsequently, silicon wafers partially covered with aluminum foil were coated together with the PC samples. The thickness of each deposited layer was determined using a profilometer (Dektak 3, Veeco Instruments Inc., Plainview, NY, USA) [23].

\subsection{Sample Surface Morphology}

The analysis of each sample's surface structure was carried out in two steps. A scanning electron microscope (SEM515, Phillips, 7 kV, WD 20 mm, FEI Company, Amsterdam, The Netherlands) was first used to perform more macroscopic examinations. The SEM images provided information on the stability of the film and whether it was intact. However, for this technique, a 7-10 nm thick gold layer must first be applied to the sample's surface to increase the conductivity. This is to avoid charging effects or even beam damage by the electron beam. A more detailed analysis of the surface was obtained with an atomic force microscope (AFM, Asylum Research, Oxford Instruments MFP-3D-BIO). The AFM was operated in contact mode with AC240-TS tips from Oxford Instruments in ambient conditions. For both microscopy techniques the measurements were repeated in at least three locations to ensure homogeneity of the surface. The AFM data obtained were then analyzed using Gwyddion (open source, version 2.58). First, a plane correction was performed. Subsequently, a mean and a median filter were used, followed by a conservative noise reduction. These steps are the same as those which were used by Catena et al. [5,8,27]. Finally, the zero level was shifted to the minimum high value of the sample surface for a unified representation. Roughness, through $R_{\mathrm{q}}$ and $R_{\mathrm{a}}$, was evaluated, and images were exported accordingly. Due to the small measuring range, however, the layer integrity cannot be determined, which is why the SEM and AFM techniques complement each other.

\subsection{Sample Surface Chemical Composition}

The chemical composition of the surface and the near-surface layers were studied by performing X-ray photoelectron spectroscopy (XPS) and near-edge X-ray absorption fine structure (NEXAFS) measurements at the synchrotron BESSY II, Helmholtz Zentrum Berlin. The measurements were performed during the low-alpha phase to avoid beam damage and strong charging at the sample surface. The HE-SGM beamline was used, which is described in detail elsewhere [30]. The beamline is equipped with an extra electron gun to compensate for beam-induced charging effects on the sample surfaces, which are still present during the low-alpha phase. Both techniques are used to investigate the carbon bond states present at the surface/near-surface region.

The XPS investigations were divided into two steps. First, a full spectrum (survey) from 0 to $700 \mathrm{eV}$ was measured to study the overall chemical composition of each sample's surface. Subsequently, the C1s peaks were analyzed in detail and evaluated with CasaXPS (software version 2.3.18, Casa Software Ltd., Teignmouth, UK). For the analysis, the C1s peaks were placed at $284.8 \mathrm{eV}$ to compensate for any static charge present [31]. The fractions of $\mathrm{sp}^{2}, \mathrm{sp}^{3}, \mathrm{C}-\mathrm{O}$ and $\mathrm{C}=\mathrm{O}$ bonds in the total $\mathrm{C} 1$ s peak were determined via peak deconvolution. When plotting in the final diagram, the $\mathrm{C}=\mathrm{O}$ bonds were evaluated as $\mathrm{sp}^{2}$ bonds and the $\mathrm{C}-\mathrm{O}$ fractions as $\mathrm{sp}^{3}$ bonds. To ensure the homogeneity of the sample surfaces and to check correctness, the measurements were repeated in at least two locations on the surface.

During the NEXAFS studies, both the C K-edge and the O K-edge were measured on the sample surfaces. The O K-edge was used to check the samples for the presence or absence of oxygen on the surface. The measurement of the $\mathrm{C}$ K-edge was also repeated in at least two locations to ensure correctness. The angle between the sample and the detector was $55^{\circ}$ during the measurements. The measurements were realized in partial electron yield (PEY). A counter voltage was applied to the detector and not all electrons emerging from the sample surface during the $X$-ray irradiation reached the detector. Only electrons that have exited close to the surface have the necessary energy to reach the 
detector, and the measurement is therefore very surface-sensitive [30]. The C K-edge was evaluated according to Watt et al. [32] using the commercial software Origin 8.1. Further investigations of the spectra were then performed with a self-written peak-evaluation program.

\section{Results and Discussion}

SEM measurements were performed to verify the condition of the coatings. The results for the range of thin films (up to $100 \mathrm{~nm}$ ) are displayed in Figure 1. Shown are the oxygen plasma-treated sample (a), the films of $10-50 \mathrm{~nm}$ a-C:H thickness in $10 \mathrm{~nm}$ steps (b-f) and the $100 \mathrm{~nm}$ a-C:H film (g). There were no changes in the state of the deposited layers between 50 and $100 \mathrm{~nm}$.
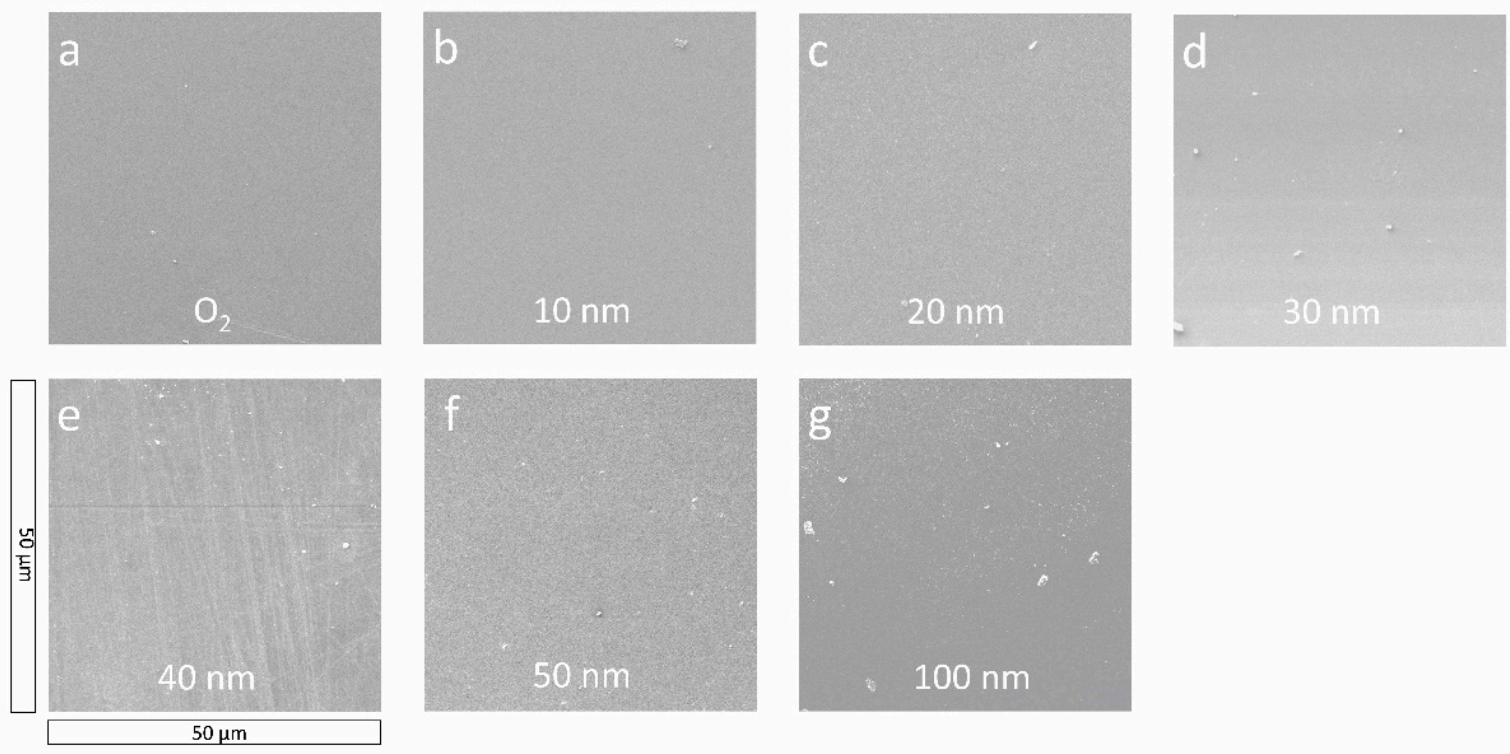

Figure 1. SEM images for the thin a-C:H layers on PC. Shown are the $\mathrm{O}_{2}$-treated PC sample (a); a-C:H deposited in thicknesses from 10 to $50 \mathrm{~nm}(\mathbf{b}-\mathbf{f})$ and $100 \mathrm{~nm}(\mathbf{g})$.

The $\mathrm{O}_{2}$-treated sample in Figure 1a shows a smooth, clean surface. Only a few particles are visible on the surface. When a $10 \mathrm{~nm}$ a-C:H layer was applied (Figure 1b), a homogeneous, closed layer was formed. With increasing layer thickness, this behavior remained unchanged (Figure 1c,d). When the a-C:H layer reached $40 \mathrm{~nm}$, the sample showed many trace-like structures in the SEM. This was probably due to a scratched surface of the sample during production. A reorganization of the layer would also be conceivable (e.g., stress-induced [33]), but the structures were probably too directional for this. Both the 50 and $100 \mathrm{~nm}$ samples (Figure 1f,g) had homogeneous, closed layers.

The SEM measurements of the thicker layers are shown in Figure 2, starting with $200 \mathrm{~nm}$ a-C:H layer thickness (Figure 2a). The homogeneous, closed surface already observed for the $100 \mathrm{~nm}$ sample continued for the 200 and $300 \mathrm{~nm}$ samples (Figure $2 \mathrm{~b}$ ). However, the deposition of a $400 \mathrm{~nm}$ thick a-C:H layer led to a layer failure on PC. In Figure $2 c$, the cracks that run through the film are clearly visible. This was most likely due to excessive stress in the film. These stresses occur when there is a high proportion of $\mathrm{sp}^{3}$ bonds in the system $[34,35]$. When they reach a critical value, the system ruptures and the stress is released. For $500 \mathrm{~nm}$ a-C:H on PC (Figure 2d), the layer was again homogeneous and closed (=stable). This held up to a film thickness of $800 \mathrm{~nm}$ (not shown here). At $900 \mathrm{~nm}$ (Figure 2e), however, the system was again unstable. That layer also cracked due to stress. From a film thickness of $1000 \mathrm{~nm}$ (Figure 2f), the film remained closed and homogeneous up to $2000 \mathrm{~nm}$ (Figure 2j). 

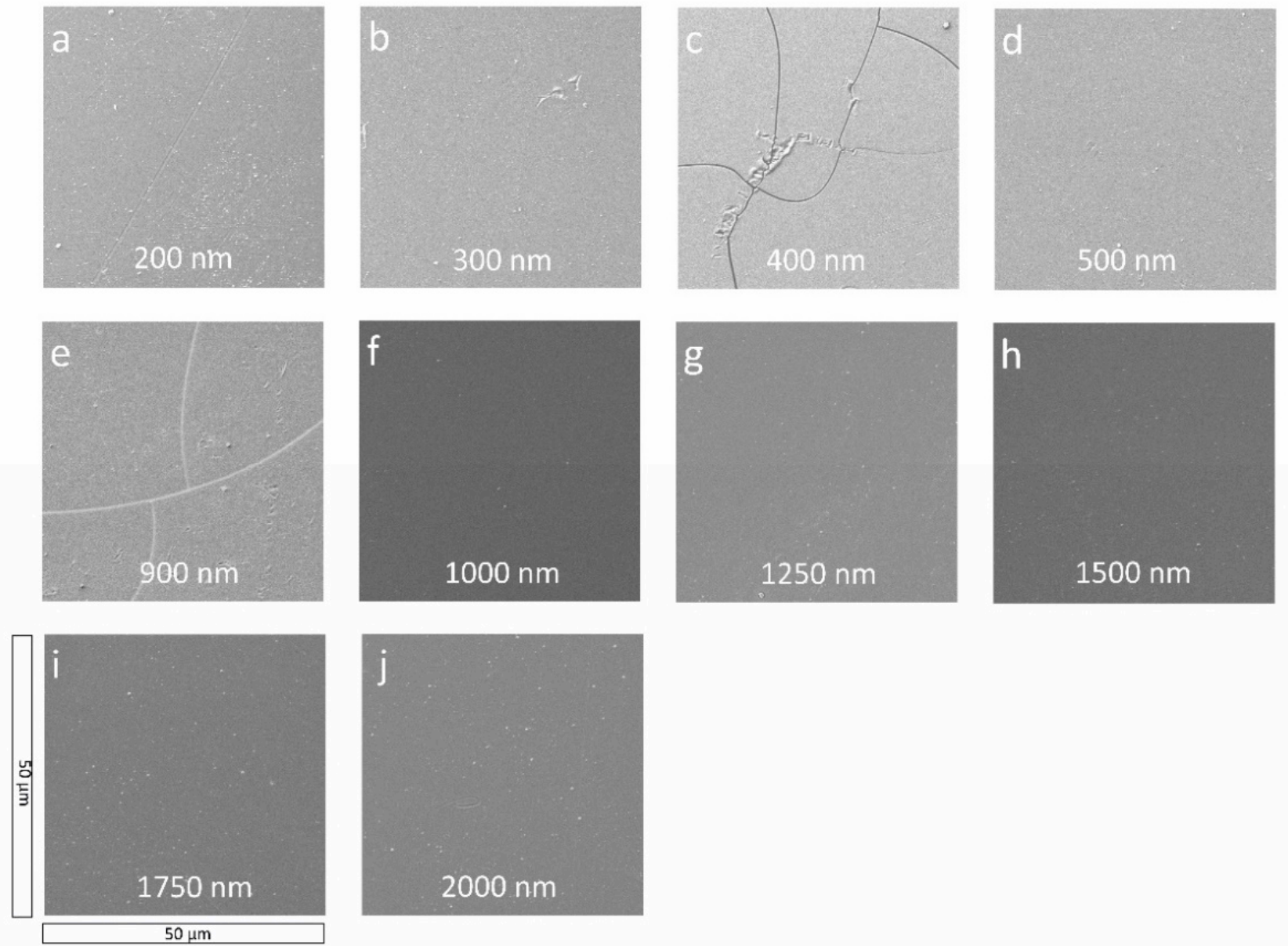

Figure 2. SEM results for thick a-C:H layers deposited on PC. Shown are the film thicknesses of $200 \mathrm{~nm}(\mathbf{a})$ to $2000 \mathrm{~nm}(\mathbf{j})$.

Figure 3 shows the three-dimensional images of the AFM measurements. The respective values for the roughness are given in Table 1 . The $\mathrm{O}_{2}$ treated sample (a) was relatively smooth with a roughness $R_{\mathrm{a}}$ of $2.069 \mathrm{~nm}$, but the surface contained particles already visible in the SEM. With the application of a $10 \mathrm{~nm}$ a-C:H layer, the surface remained homogeneous. At $20 \mathrm{~nm}$ (c) a granular structure was formed. The formation of these grains is a sign that the interlayer phase is completed and normal a-C:H growth begins $[5,8]$. At $30 \mathrm{~nm}$ thickness (d) the most homogeneous surface was present ( $R_{\mathrm{a}}$ of 0.789$)$, and only single, small particles were visible. One a-C:H layer was most likely just completed and the next one was beginning to form. The same was applicable to the sample with $50 \mathrm{~nm}$ layer thickness (f), but the process was already more advanced.

Figure 4 shows the results of the AFM measurements for layer thicknesses from $200 \mathrm{~nm}$ (a) to $2000 \mathrm{~nm}$ (i). The corresponding roughness values are listed in Table 1. For $200 \mathrm{~nm}$ a-C:H film thickness (Figure 4a), multiple but small grains are visible. At the thickness of $300 \mathrm{~nm}$ (b), the number of grains decreased just slightly, but they increased strongly in size. The situation was similar for the $400 \mathrm{~nm}$ layer thickness (c). Relatively fewer and smaller grains were on the $500 \mathrm{~nm}$ layer (d). The $1000 \mathrm{~nm}$ sample (e), like the $2000 \mathrm{~nm}$ sample (i), was hardly occupied by grains. The 1250, 1500 and $1750 \mathrm{~nm}$ layers showed pronounced grain structures, although of varying intensity $(\mathrm{f}-\mathrm{h})$. 

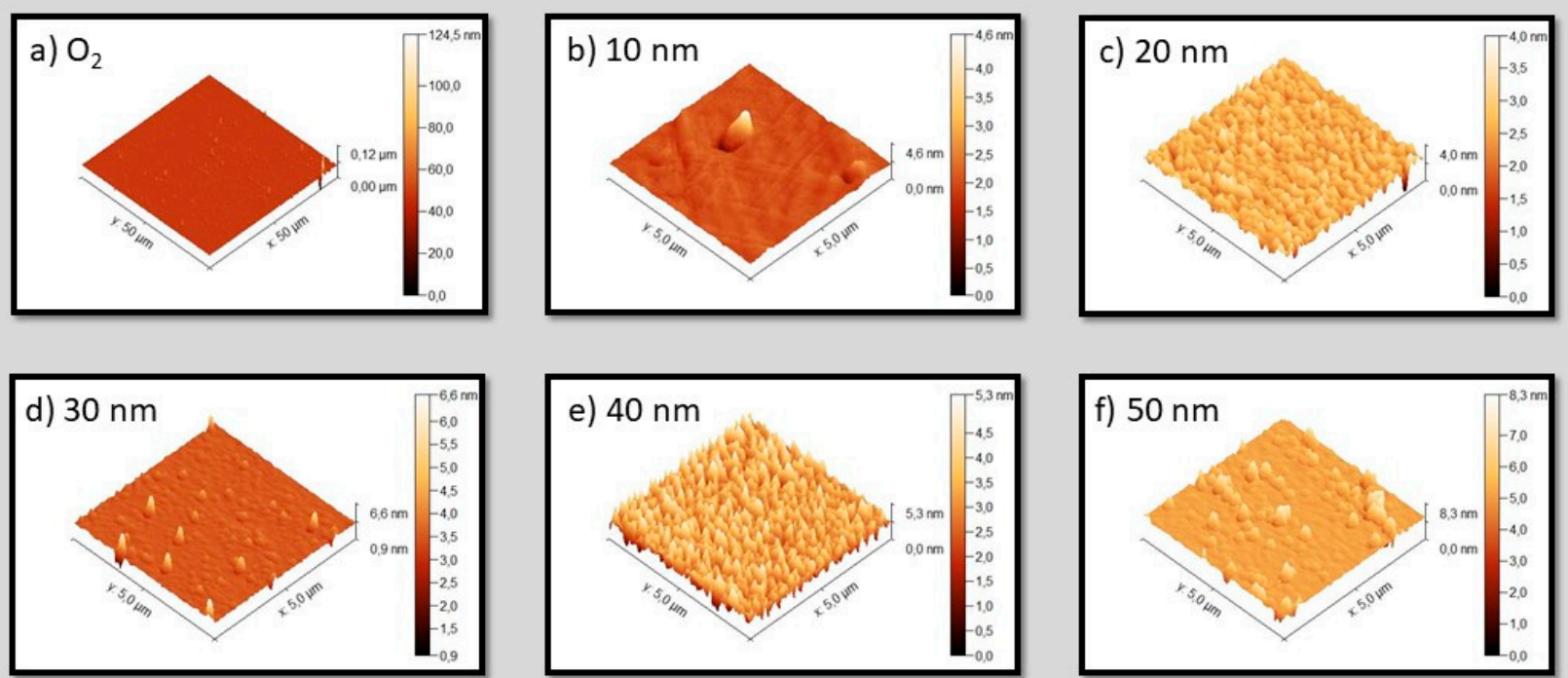

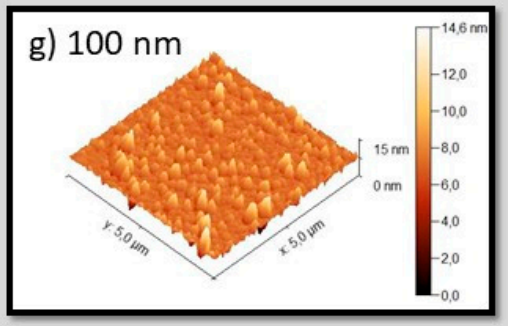

Figure 3. AFM 3D-images for the $\mathrm{O}_{2}$ plasma-treated PC sample (a) and PC coated with thin a-C:H layers from $10 \mathrm{~nm}(\mathbf{b})$ to $100 \mathrm{~nm}(\mathrm{~g})$.

Table 1. AFM roughness values $R_{\mathrm{a}}$ and $R_{\mathrm{q}}$ : analyzed are the $\mathrm{O}_{2}$ plasma-treated PC sample and PC samples coated with a-C:H layers of various thickness in ascending order.

\begin{tabular}{ccc}
\hline Sample & $\begin{array}{c}\boldsymbol{R}_{\mathbf{a}} \\
{[\mathbf{n m}]}\end{array}$ & $\begin{array}{c}\boldsymbol{R}_{\mathbf{q}} \\
{[\mathbf{n m}]}\end{array}$ \\
\hline $\mathrm{O}_{2}$ & $2.069 \pm 1.578$ & $5.256 \pm 15.320$ \\
10 & $2.759 \pm 2.095$ & $4.775 \pm 5.086$ \\
30 & $2.363 \pm 0.401$ & $2.999 \pm 0.649$ \\
40 & $0.789 \pm 0.240$ & $1.350 \pm 0.581$ \\
50 & $3.812 \pm 0.719$ & $4.932 \pm 1.091$ \\
100 & $2.940 \pm 1.744$ & $5.155 \pm 2.925$ \\
200 & $5.161 \pm 1.383$ & $7.140 \pm 2.134$ \\
300 & $4.978 \pm 1.381$ & $6.946 \pm 2.162$ \\
400 & $5.729 \pm 3.585$ & $9.890 \pm 6.357$ \\
500 & $3.850 \pm 1.968$ & $6.783 \pm 3.564$ \\
1000 & $2.048 \pm 1.395$ & $3.886 \pm 3.613$ \\
1250 & $7.443 \pm 7.519$ & $15.250 \pm 16.670$ \\
1500 & $4.546 \pm 1.454$ & $6.432 \pm 2.398$ \\
1750 & $3.790 \pm 1.080$ & $5.161 \pm 2.387$ \\
2000 & $3.460 \pm 1.274$ & $4.813 \pm 2.868$ \\
\hline
\end{tabular}



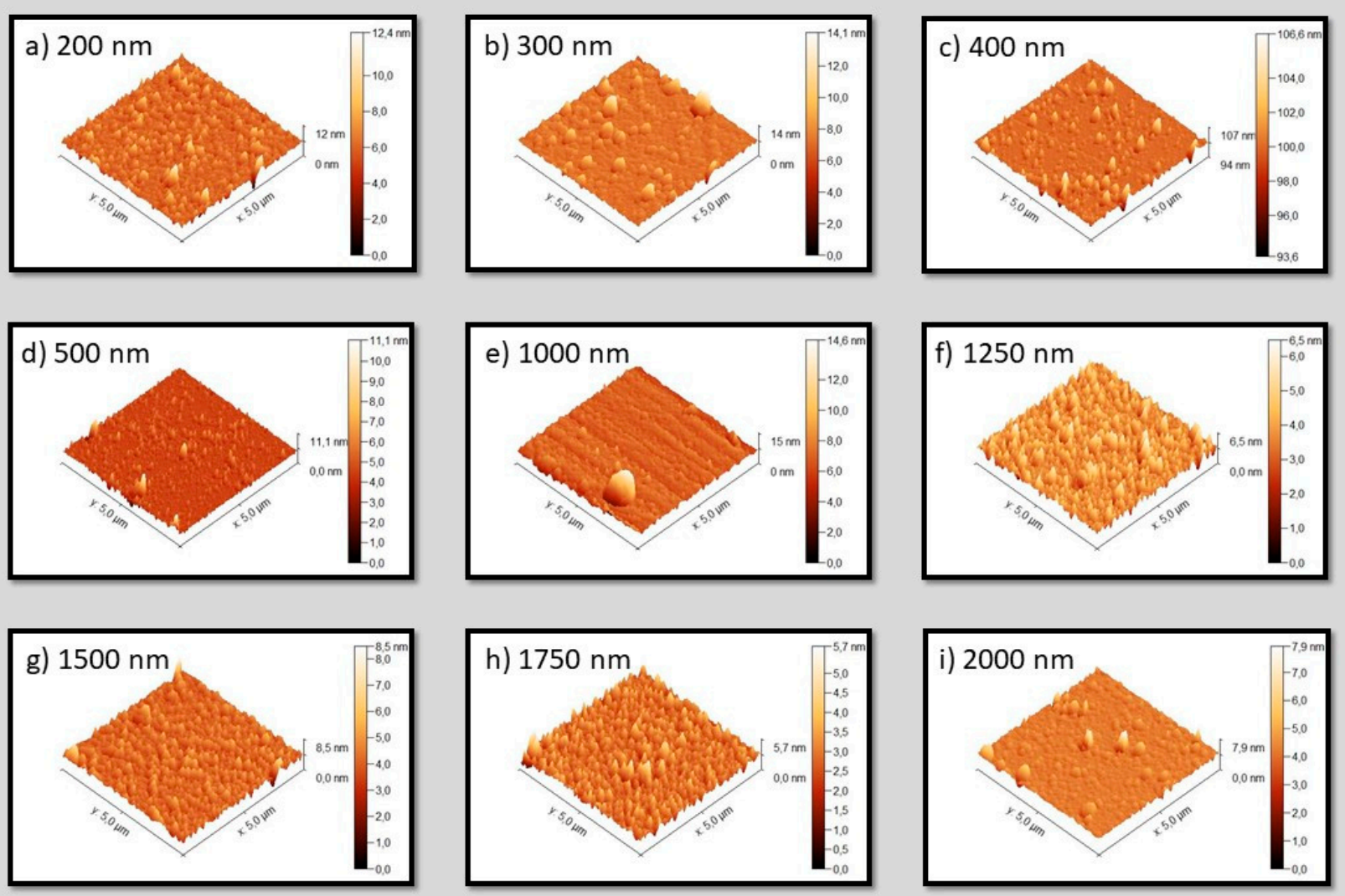

Figure 4. AFM 3D-images for PC samples coated with thick a-C:H layers from $200 \mathrm{~nm}$ (a) to $2000 \mathrm{~nm}(\mathbf{i})$.

The XPS results for thin a-C:H layers on PC are shown in Figure 5. The percentages of $\mathrm{sp}^{2}$ and $\mathrm{sp}^{3}$ binding after deconvolution of the C1s peak with CasaXPS are plotted against the layer thickness in nanometers. The positions of the peaks were determined with the help of the NIST database and from other sources [19,20,36-38]. For the plot, the C-O bonds were counted as $\mathrm{sp}^{3}$ bonds and the $\mathrm{C}=\mathrm{O}$ bonds as $\mathrm{sp}^{2}$ bonds. The respective values for the whole XPS measurements are shown in Table 2 . The relatively high oxygen content of some of these layer surfaces is probably due to saturation of still active bonds on the surface, which occurs after plasma treatment when the vacuum chamber is vented with ambient air. Due to the relatively high surface sensitivity, the saturation of the remaining surface bonds has a great influence on the measurement results obtained. The saturation of broken bonds by internal stress in the layers is also possible. The analysis of the thin layers in $10 \mathrm{~nm}$ steps is essential to determining the interlayer thickness. For the $\mathrm{O}_{2}$ plasma-treated raw polymer, $15 \% \mathrm{sp}^{3}$ bonded and $85 \% \mathrm{sp}^{2}$ bonded carbon were deduced. By depositing an a-C:H layer on $\mathrm{PC}$, the $\mathrm{sp}^{3}$ fraction increased and dominated the carbon network with a fraction of $55 \%$. When a layer thickness of $20 \mathrm{~nm}$ was reached, the $\mathrm{sp}^{2}$ and $\mathrm{sp}^{3}$ bonds were balanced. As the a-C:H thickness increased further, the layer behavior changed drastically. The network was strongly $\mathrm{sp}^{2}$ dominated (95\%), and the $\mathrm{sp}^{3}$ bonding disappeared almost completely. In the AFM images, the pure layer growth on the surface was also visible (Figure 3c,d). The fraction of $\mathrm{sp}^{2}$ bonds was low with a layer thickness of $40 \mathrm{~nm}$, but remained highly a-C:H dominated $(70-80 \%)$ up to a layer thickness of $100 \mathrm{~nm}$. Based on the strongly changing layer behavior in the XPS measurements, the interlayer thickness was estimated to be about $20 \mathrm{~nm}$. 


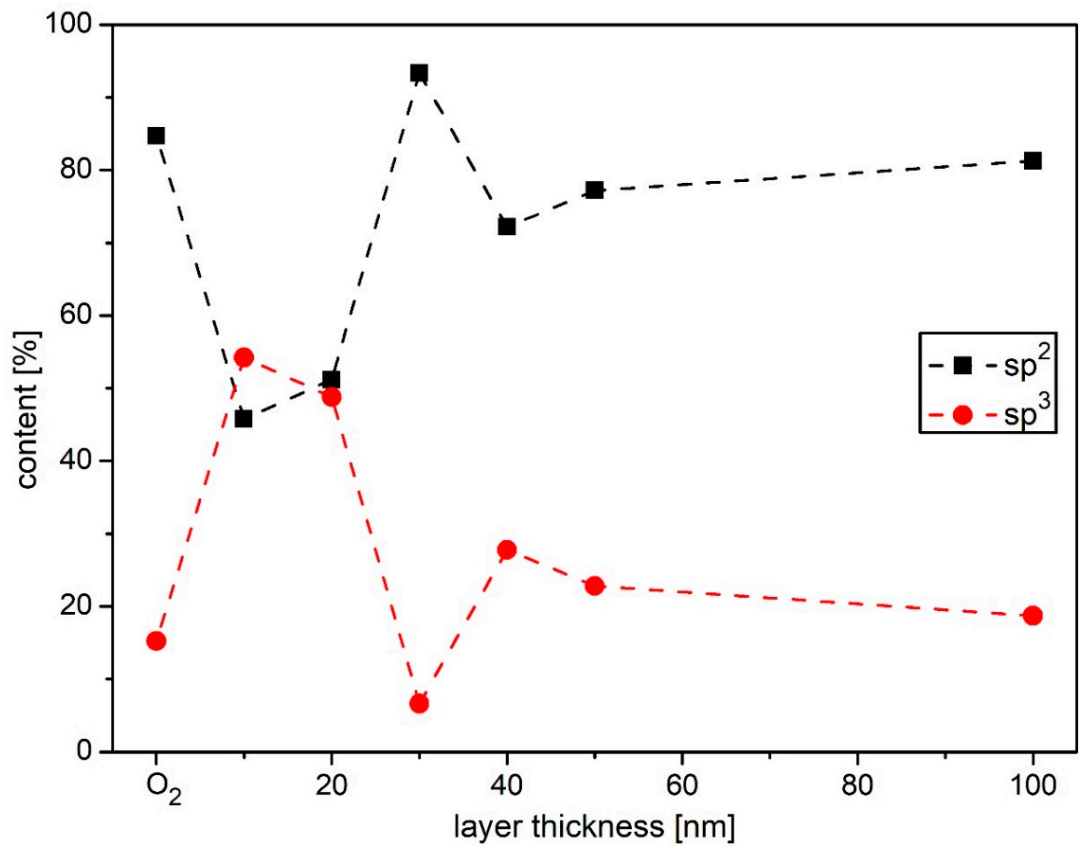

Figure 5. XPS results for thin a-C:H layers on PC. The $\mathrm{sp}^{2}$ content (black squares) and $\mathrm{sp}^{3}$ (red circles) bound carbon are plotted against layer thickness (dashed lines show only a trend).

Table 2. Results of XPS measurements separated into the percentages of $\mathrm{sp}^{2}, \mathrm{sp}^{3}, \mathrm{C}-\mathrm{O}$ and $\mathrm{C}=\mathrm{O}$ binding to the $\mathrm{C} 1$ s peak after deconvolution.

\begin{tabular}{ccccc}
\hline Sample & $\begin{array}{c}\mathbf{s p}^{\mathbf{2}} \\
{[\mathbf{\%}]}\end{array}$ & $\begin{array}{c}\mathbf{s p}^{\mathbf{3}} \\
{[\mathbf{\%}]}\end{array}$ & $\begin{array}{c}\mathbf{C}-\mathbf{O} \\
{[\%]}\end{array}$ & $\begin{array}{c}\mathbf{C}=\mathbf{O} \\
{[\%]}\end{array}$ \\
\hline $\mathrm{O}_{2}$ & 83.49 & 4.55 & 10.70 & 1.26 \\
10 & 42.55 & 38.59 & 15.65 & 0.37 \\
20 & 48.58 & 43.42 & 5.38 & 2.63 \\
30 & 90.14 & 4.24 & 2.39 & 3.24 \\
40 & 72.19 & 7.02 & 20.79 & 0.00 \\
50 & 74.58 & 12.97 & 9.84 & 2.62 \\
100 & 79.39 & 11.43 & 7.29 & 1.90 \\
200 & 34.02 & 48.81 & 14.04 & 0.12 \\
300 & 51.77 & 35.44 & 12.26 & 1.69 \\
400 & 80.51 & 4.05 & 13.76 & 8.91 \\
500 & 68.10 & 22.99 & 0.00 & 10.73 \\
1000 & 23.63 & 50.68 & 14.96 & 0.65 \\
1250 & 84.95 & 14.40 & 0.00 & 0.00 \\
1500 & 83.12 & 16.88 & 0.00 & 1.17 \\
1750 & 82.94 & 10.70 & 5.20 & 1.05 \\
2000 & 82.58 & 0.31 & 16.06 &
\end{tabular}

The results of the XPS measurements for the thick a-C:H layers deposited on PC begin at a thickness of $100 \mathrm{~nm}$ and are plotted in Figure 6. The dominant bond changed briefly to $\mathrm{sp}^{3}(63 \%)$ at a film thickness of $200 \mathrm{~nm}$. As the film thickness increased, the proportion of $\mathrm{sp}^{2}$ bonds increased again at the expense of the $\mathrm{sp}^{3}$ bonds, and again reached over $80 \%$. In the course of further coating, the proportion of $\mathrm{sp}^{2}$ bonds decreased again until at a film thickness of $1000 \mathrm{~nm}$, the $\mathrm{sp}^{3}$ bond again dominated. The proportions retained were similar to those at 10 and $200 \mathrm{~nm}$. As before, the quantity of $\mathrm{sp}^{3}$ bonds decreased again with increasing film thickness. After reaching an a-C:H layer of $1250 \mathrm{~nm}$, the two bonds remained almost constant up to a film thickness of $2000 \mathrm{~nm}$. After $1250 \mathrm{~nm}$, the a-C:H growth of the film changed compared to the previous behavior. The strongly reduced proportion of $\mathrm{sp}^{3}$ bonds was due to dehydration of the layer. In this process, hydrogen leaves the layer and lowers the amount of $\mathrm{sp}^{3}$-bonded carbons. The free bonds 
are converted into $\mathrm{sp}^{2}$ hybridized carbons. Thus, re-hybridization of the carbon atom orbitals occurs. This behavior has already been observed for several polymers coated with a-C:H $[8,28,29]$. Figure 7 presents exemplary deconvolutions of the 10, 100 and $1000 \mathrm{~nm}$ a-C:H layer thicknesses for the C1s peak using CasaXPS.

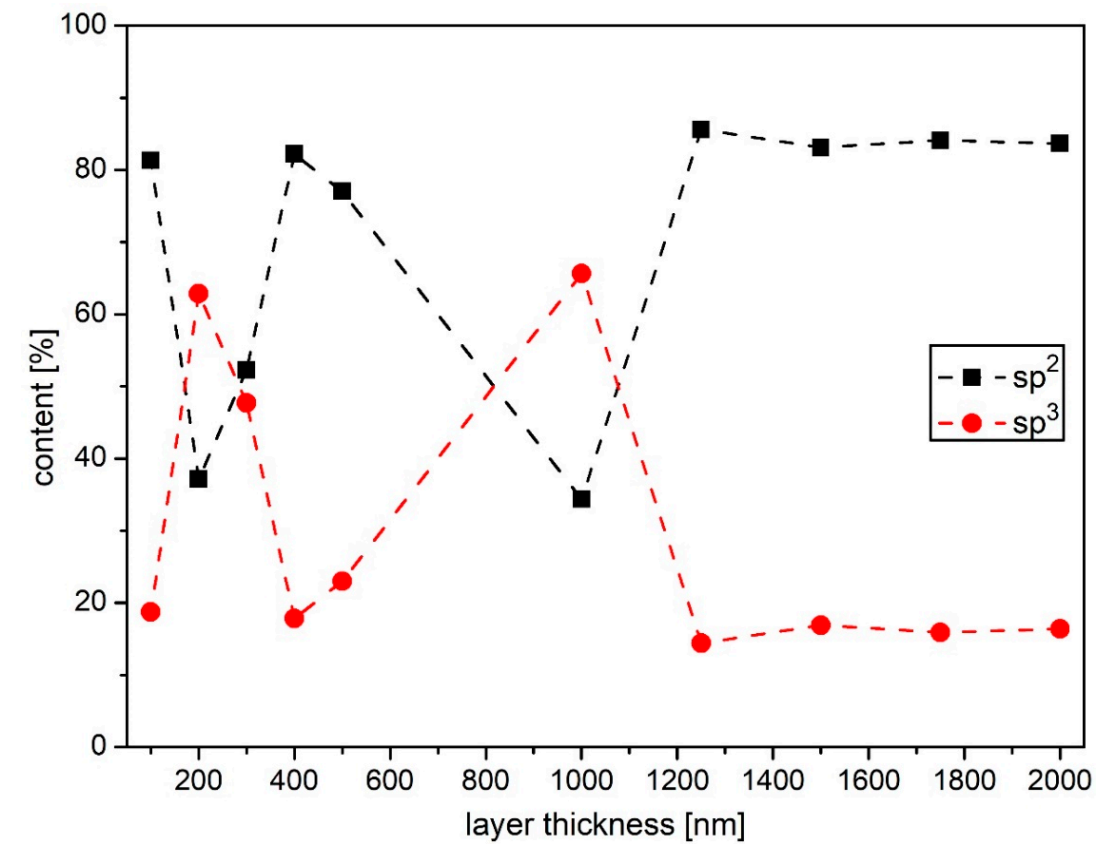

Figure 6. XPS results for thick a-C:H layers deposited on PC, up to $2000 \mathrm{~nm}$. The black squares are the $\mathrm{sp}^{2}$ content and the red circles are the $\mathrm{sp}^{3}$ bound carbons plotted against layer thickness (dashed lines only show a trend).

$10 \mathrm{~nm}$

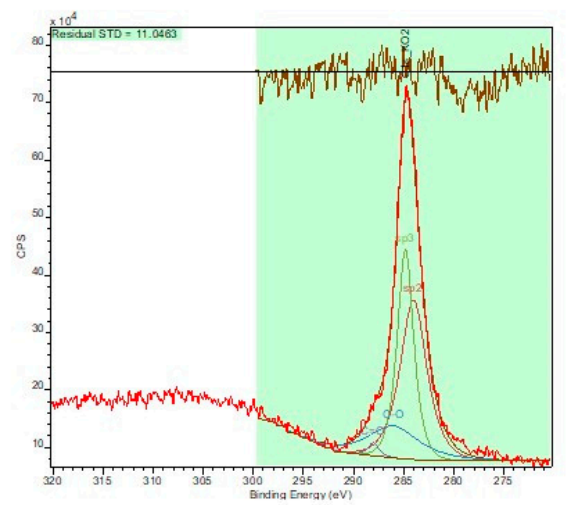

$100 \mathrm{~nm}$

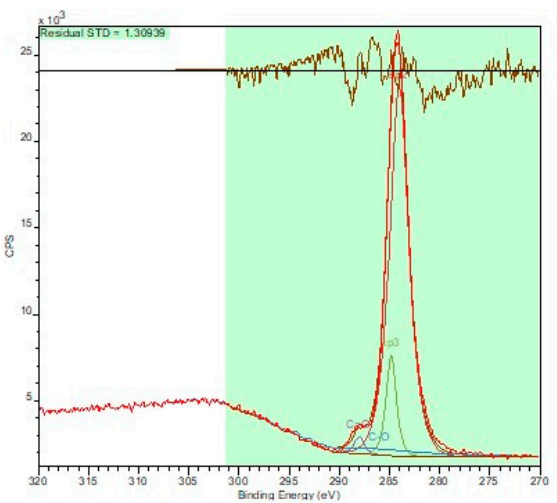

$1000 \mathrm{~nm}$

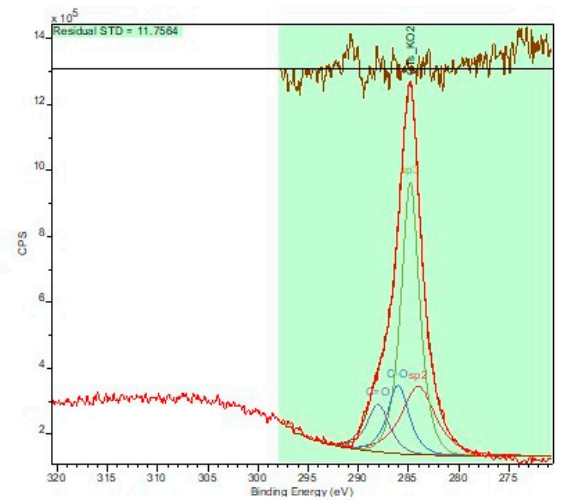

Figure 7. Exemplary XPS peak deconvolution for the a-C:H layer thicknesses of 10, 100 and $1000 \mathrm{~nm}$. The analysis was performed on the $\mathrm{sp}^{2}, \mathrm{sp}^{3}, \mathrm{C}-\mathrm{O}$ and $\mathrm{C}=\mathrm{O}$ fractions using CasaXPS software.

A striking feature is the almost periodic behavior of the carbon bonds over the layer thickness. The $\mathrm{sp}^{2}$ bond dominated, and in a short film thickness interval the $\mathrm{sp}^{3}$ bond was dominant. With each step, however, the proportion of $\mathrm{sp}^{3}$ bonds increased slightly $(55 \%$, $63 \%$ and $65 \%$ ). After the $\mathrm{sp}^{3}$ bond was dominant for a short time, the bond ratio suddenly changed to a strongly $\mathrm{sp}^{2}$ dominated carbon network. A comparison with SEM images shows that this change of the dominant bond was accompanied by layer failure. The first change occurred at $20 \mathrm{~nm}$ film thickness (Figure 5). With a short delay, no layer failure occurred at $40 \mathrm{~nm}$, but the sample surface was covered with fine, thread-like structures 
(Figure 1e). It is possible that the stress caused by the $\mathrm{sp}^{3}$ bonds was not yet strong enough to completely crack the layer. However, it is noticeable that there was a strong $\mathrm{C}-\mathrm{O}$ content of $20.79 \%$ (Table 2). It is possible that individual, broken C-C bonds were saturated with oxygen from the environment. As the layer grew from 300 to $400 \mathrm{~nm}$, the dominant bond changed again from $\mathrm{sp}^{3}$ to $\mathrm{sp}^{2}$. The SEM images for the $400 \mathrm{~nm}$ sample (Figure 2c) showed a clear cracking of the layer, which took place shortly after the change of the dominant bond. The same applied to the change to the $900 \mathrm{~nm}$ sample (Figure 2e). In the XPS the change took place while reaching $1000 \mathrm{~nm}$ a-C:H on the sample-thereby only after the layer failure was visible in the SEM. Most likely the fraction of $\mathrm{sp}^{3}$ bonds had already reached its highest value at $900 \mathrm{~nm}$ and at the step to $1000 \mathrm{~nm}$ it decreased, which was accompanied with a stress release (=breakup of the layer). Unfortunately, the $900 \mathrm{~nm}$ sample was not measurable in the XPS. This change from $\mathrm{sp}^{3}$ to $\mathrm{sp}^{2}$ as the dominant bond with a subsequent layer failure has already been observed for other polymers $[19,20,23,29]$. The more pronounced the interlayer, the greater the delay. In the case of PC, it is very weak with a thickness of $20 \mathrm{~nm}$, and the crack in the layer follows more or less directly after the change in the dominant bond (XPS: change in bond at $20 \mathrm{~nm}$, SEM striking layer behavior at $40 \mathrm{~nm}$ ). As revealed for polyhydroxy butyrate, the interlayer is of average strength, ending in a delay of $100 \mathrm{~nm}$ [20]; for polybutylene adipate terephthalate the interlayer is very pronounced with a delay of $200 \mathrm{~nm}$ between the change and the layer failure. Even after failure of the layer, it continues to adhere to the polymer instead of rolling up [23]. Both polyamide 6 (PA6) and HDPE have very pronounced interlayers $(40 \mathrm{~nm})[28,29]$. In both cases, the bonding ratio is very stable, and the layers only break down at very high layer thicknesses. In the case of PA6, no change from $\mathrm{sp}^{3}$ to $\mathrm{sp}^{2}$ as the dominant bond could be detected. However, at the step to $1500 \mathrm{~nm}$ film thickness, there was a very strong drop in $\mathrm{sp}^{3}$ bonds (zone of dehydrogenation), followed by film failure at $1750 \mathrm{~nm}$ [29]. For HDPE, there was a change from $\mathrm{sp}^{3}$ to $\mathrm{sp}^{2}$ at $50 \mathrm{~nm}$, but layer failure was only observable at $1000 \mathrm{~nm}[8,28]$. As in previous studies, the change from $\mathrm{sp}^{2}$ to $\mathrm{sp}^{3}$ as the dominant bond had no effect on the integrity of the layer [19,20,23,29].

For further analysis of the chemical composition of the coating surface, NEXAFS investigations were performed. The results of the C K-edge are plotted in Figure 8. The determination of the peak location was based on the work of other groups and specified as follows: C $=\mathrm{C} \pi(284.85 \mathrm{eV}), \mathrm{C}-\mathrm{H}(286.15 \mathrm{eV}), \mathrm{C}-\mathrm{C}(288.35 \mathrm{eV})$ and $\mathrm{C}=\mathrm{C} \sigma(292.55 \mathrm{eV})$ [39-43]. The spectra were analyzed as described in Section 2.3. The diagram is divided into three different thickness ranges: A includes the 0-50 nm a-C:H layer thicknesses; B includes the layers from 100 to $500 \mathrm{~nm}$; and finally, C layers from 1000 to $2000 \mathrm{~nm}$. For better clarification, there is a zoom of the region from 284 to $289 \mathrm{eV}$ to the right of each. In Figure $8 \mathrm{~A}$, it can be seen that the ratio of the $\mathrm{C}=\mathrm{C} \pi$ peak to the $\mathrm{C}-\mathrm{C}$ peak tended to tilt in favor of the $\mathrm{C}=\mathrm{C} \pi$ peak with increasing film thickness. Thus, the $\mathrm{sp}^{2}$ bonding was more pronounced with increasing film thickness at the expense of the $\mathrm{sp}^{3}$ bonding. At $50 \mathrm{~nm}$ film thickness, the $C-C$ peak was barely visible at $288.15 \mathrm{eV}$, and the $\mathrm{C}=\mathrm{C} \pi$ was relatively emphasized at $284.85 \mathrm{eV}$. This is also consistent with the results already observed in the XPS (Figure 5). A new feature is that the C K-edge formed a strong C-H slope for the layer thicknesses of 20 and $40 \mathrm{~nm}$. These were the thicknesses with the largest numbers of grains on the surface just before the end of the layer. A correlation is clearly visible. When the layer was complete and grains were barely visible, this peak disappeared (Figure $3 b, \mathrm{~d}$, f and Figure 8A). The $100 \mathrm{~nm}$ a-C:H layer thickness on PC again showed the peak for the $\mathrm{C}-\mathrm{H}$ bond (Figure 8B). Again, many grains are visible on the surface in the AFM (Figure 3g). The $\mathrm{C}=\mathrm{C} \pi$ peak is strongly emphasized, the $\mathrm{C}-\mathrm{C}$ peak only weakly developed. This is again in agreement with the XPS measurements. At 200 and $300 \mathrm{~nm}$ the $\mathrm{C}=\mathrm{C} \pi$ peak decreased, and the C-C peak at 288.15 is more pronounced. Already in the XPS measurements, it could be seen that the fraction of $\mathrm{sp}^{3}$ was higher (Figure 6). The flanks of the $\mathrm{C}-\mathrm{H}$ bond were also recognizable. The AFM images (Figure $4 a, b$ ) also showed some grains on the surface of the layer. When reaching the $500 \mathrm{~nm}$ layer thickness, the $\mathrm{C}-\mathrm{H}$ peak almost disappeared and was hardly recognizable. The AFM image showed here (Figure 4d) only isolated 
and mostly very small grains on the surface. The C-K edge of the $1000 \mathrm{~nm}$ a-C:H layer on PC is plotted in Figure 8C. Unfortunately, the measurement in NEXAFS proved to be extremely difficult, so the curve was plotted here more for the purpose of completeness. The C-C peak seems to be superimposed or broadened by a possible charge, which would make an evaluation very error-prone, so it will not be discussed further, except for the non-existent $\mathrm{C}-\mathrm{H}$ peak. As expected from the previous results, the AFM image (Figure 4e) hardly shows any grain structures. For the thicknesses of 1250 and $1750 \mathrm{~nm}(1500 \mathrm{~nm}$ was not measurable), the ratios of the $\mathrm{C}=\mathrm{C} \pi$ and the $\mathrm{C}-\mathrm{C}$ peak were about the same, although both peaks are visible in a defined way. The peak of the $\mathrm{C}-\mathrm{H}$ bond is also observable, although it is weaker for the larger of the two layer thicknesses $(1750 \mathrm{~nm})$. Compared with the AFM images (Figure 4f,h), a decrease in the density of the grains with increasing layer thickness can be seen. Finally, when the film thickness increased to $2000 \mathrm{~nm}$, the ratio again tipped in favor of the $\mathrm{C}=\mathrm{C} \pi$ peak at $284.85 \mathrm{eV}$. In the XPS, on the other hand, the ratio of $\mathrm{sp}^{2}$ to $\mathrm{sp}^{3}$ was almost constant from $1000 \mathrm{~nm}$ layer thickness, so the $\mathrm{C}$ K-edge result for the $2000 \mathrm{~nm}$ a-C:H layer differs here from that of the XPS measurements. In the AFM images hardly any grains are visible for this layer thickness (Figure 4i), and also the C-H peak is no longer present in the NEXAFS measurements.

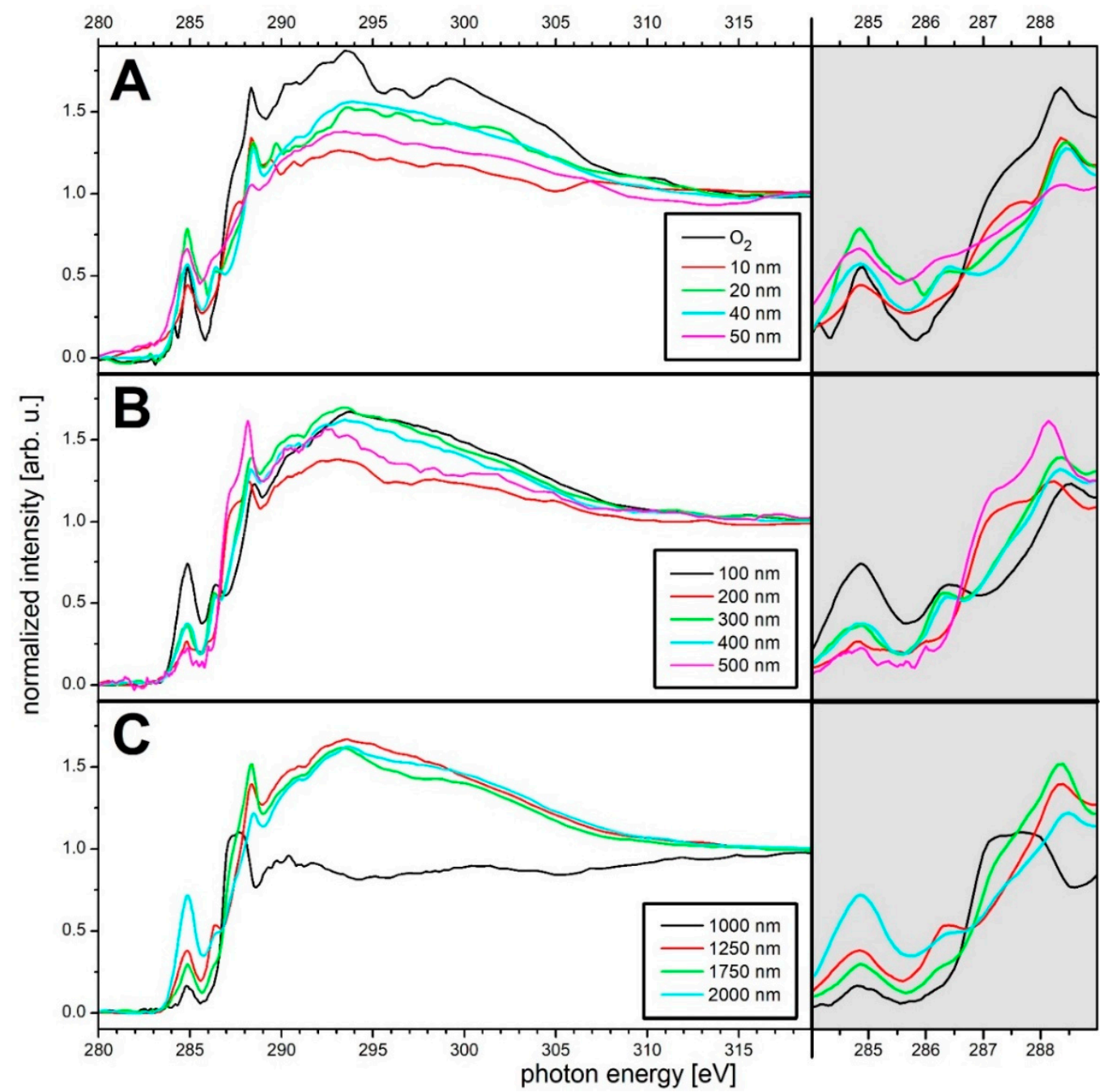

Figure 8. NEXAFS C K-edge spectra for a-C:H layers of various thicknesses deposited on PC. (A) The a-C:H thicknesses 0-50 nm, (B) 100-500 nm and (C) 1000-2000 nm. On the left are the full spectra (280-320 eV); on the right is a magnification of the region from 284 to $289 \mathrm{eV}$. Here are the peaks located for C=C $\pi(284.85 \mathrm{eV}), \mathrm{C}-\mathrm{H}(286.15 \mathrm{eV})$ and C-C $(288.15 \mathrm{eV})$. 
Overall, however, the two methods correspond to each other and a correlation between grain density on the layer surface and the formation of a C-H peak was found on the basis of the AFM measurements. Apart from minor deviations (for example, a somewhat more pronounced C-H peak would have been expected with a film thickness of $200 \mathrm{~nm}$, Figure 4a), this pattern is confirmed. Thus, with the help of the NEXAFS measurement, conclusions can be drawn about the growth status of the current layer. A possible explanation for the more defined $\mathrm{C}-\mathrm{H}$ peak with many grains is the size of the surface that is measured. If the layer is smooth, the total surface area is smaller than if the layer is covered with grains. Since the hydrogens represent the ends of the carbon chains, a larger total surface area means that there are also more ends that are detected.

\section{Conclusions}

Depositions of a-C:H layers were successfully arranged on the polymer PC in various thicknesses (10-2000 nm). The coating was applied by RF-PECVD with acetylene plasma in a vacuum chamber. The obtained layers were subsequently investigated by SEM, AFM, and synchrotron assisted XPS and NEXAFS. Particular attention was paid to the region from $0-100 \mathrm{~nm}$, where the interlayer is formed, which is responsible for the connection of the layer to the base material. It was determined to be $20 \mathrm{~nm}$ thick by XPS and AFM measurements. In the AFM, grains are visible from this thickness onwards, which indicate normal a-C:H growth. The XPS shows a completely changing bonding behavior of the carbon atoms on the surface of the layer, which indicates a change in the growth process.

With the SEM measurements, unstable layer thicknesses could be found, where the layer cracks due to internal stresses $(400 \mathrm{~nm}, 900 \mathrm{~nm})$. If the XPS measurements are considered, it is evident that these layer stabilities immediately follow the change from $\mathrm{sp}^{3}$ to $\mathrm{sp}^{2}$ as the dominant bond in the carbon network. Rigid $\mathrm{sp}^{3}$ bonds break due to internal stress and the carbon atoms reorganize to $\mathrm{sp}^{2}$ bonds. The range of dehydrogenation for the a-C:H layers on PC could be determined by XPS to the thickness range of 1250-2000 nm. Here, hydrogen leaves the layers and formerly $\mathrm{sp}^{3}$ bonded carbon atoms reorganize into a strong $\mathrm{sp}^{2}$ dominated network. The NEXAFS investigations confirm the overall results of the XPS. In addition, a correlation between the number and size of grains on the layer surface and the formation of the $\mathrm{C}-\mathrm{H}$ peak in the $\mathrm{C}$ K-edge was found. The more the surface is maximized by the grains, the more accentuated is the $\mathrm{C}-\mathrm{H}$ peak. Since the hydrogen atoms terminate the carbon chains and towards the outside, it is obvious that the larger the surface area, the more $\mathrm{C}-\mathrm{H}$ bonds are present.

The coatability of PC with a-C:H layers was examined and areas of unstable layer thickness were found. In addition, effects were detected that influence the surface bonding ratio. With these fundamentals, targeted modification of the surface properties, such as the application of a thin, scratch-resistant a-C:H layer for e.g., optical components, is now possible. However, further studies must be performed for respective applications.

Author Contributions: T.S., Y.W. and C.B.F. conceptualized the study, and developed and organized the processes. T.S. prepared the samples and contributed the AFM measurements. T.S. also performed the data acquisition and evaluation of XPS and NEXAFS, evaluation of SEM and AFM results, overall data curation, visualization and wrote the manuscript draft. M.F. and L.B. contributed to the acquisition of synchrotron measurements, XPS and NEXAFS. T.S. and C.B.F. validated the results, and reviewed and edited the manuscript. Both S.W. and C.B.F. contributed in terms of funding acquisition, project administration, supervision and overall guidance in the study. All authors have read and agreed to the published version of the manuscript.

Funding: T.S., L.B. and C.B.F. gratefully acknowledge the financial support (funding agreements BESSY 2: 62 and 145) provided by the Helmholtz-Zentrum Berlin (HZB), Germany.

Data Availability Statement: The data presented in this study are available on request from the corresponding author. 
Acknowledgments: The authors thank Heinz Busch (NTTF Coatings GmbH, Rheinbreitbach, Germany) for the possibility of industrial coating of the samples. Additionally, we thank Barbara Hahn, Youssef Benjillali and Mohammed Bentaouit from the University of Applied Sciences Koblenz (Department of Material Analysis, RheinAhrCampus) for the SEM equipment and measurements. We also thank Alexei Nefedov from KIT (Karlsruhe Institute for Technology, Group: Chemistry of oxidic and organic interfaces; X-ray and Electron Spectroscopy at Interfaces) for beamtime support. We thank HZB for the allocation of synchrotron radiation beamtime. The authors thankfully acknowledge the financial support by the Helmholtz-Zentrum Berlin (HZB), Germany.

Conflicts of Interest: The authors declare no conflict of interest.

\section{References}

1. Ibrahim, S.S.; Al Jaafari, A.A.; Ayesh, A.S. Physical characterizations of three phase polycarbonate nanocomposites. J. Plast. Film Sheet. 2011, 27, 275-291. [CrossRef]

2. Kausar, A. A review of filled and pristine polycarbonate blends and their applications. J. Plast. Film Sheet. 2018, 34, 60-97. [CrossRef]

3. Krishnan, A.V.; Stathis, P.; Permuth, S.F.; Tokes, L.; Feldman, D. Bisphenol-A: An estrogenic substance is released from polycarbonate flasks during autoclaving. Endocrinology 1993, 132, 2279-2286. [CrossRef]

4. Wang, Y.; Guan, W.; Fischer, C.B.; Wehner, S.; Dang, R.; Li, J.; Wang, C.; Guo, W. Microstructures, mechanical properties and tribological behaviors of amorphous carbon coatings in-situ grown on polycarbonate surfaces. Appl. Surf. Sci. 2021, 563, 150309. [CrossRef]

5. Catena, A.; Guo, Q.; Kunze, M.R.; Agnello, S.; Gelardi, F.M.; Wehner, S.; Fischer, C.B. Morphological and Chemical Evolution of Gradually Deposited Diamond-Like Carbon Films on Polyethylene Terephthalate: From Subplantation Processes to Structural Reorganization by Intrinsic Stress Release Phenomena. ACS Appl. Mater. Interfaces 2016, 8, 10636-10646. [CrossRef] [PubMed]

6. Grill, A. Plasma-deposited diamondlike carbon and related materials. IBM J. Res. Dev. 1999, 43, 147-162. [CrossRef]

7. Couderc, P.; Catherine, Y. Structure and physical properties of plasma-grown amorphous hydrogenated carbon films. Thin Solid Film. 1987, 146, 93-107. [CrossRef]

8. Catena, A.; Agnello, S.; Rösken, L.M.; Bergen, H.; Recktenwald, E.; Bernsmann, F.; Busch, H.; Cannas, M.; Gelardi, F.M.; Hahn, B.; et al. Characteristics of industrially manufactured amorphous hydrogenated carbon (a-C:H) depositions on high-density polyethylene. Carbon 2016, 96, 661-671. [CrossRef]

9. Mohagheghpour, E.; Rajabi, M.; Gholamipour, R.; Larijani, M.M.; Sheibani, S. Ion beam energy dependence of surface and structural properties of amorphous carbon films deposited by IBSD method on Ni-Cu alloy. J. Mater. Res. 2017, 32, 1258-1266. [CrossRef]

10. Paul, R.; Das, S.N.; Dalui, S.; Gayen, R.N.; Roy, R.K.; Bhar, R.; Pal, A.K. Synthesis of DLC films with different sp2/sp3 ratios and their hydrophobic behaviour. Phys. Rev. B 2008, 41, 055309. [CrossRef]

11. Feng, L.; Li, S.; Li, Y.; Li, H.; Zhang, L.; Zhai, J.; Song, Y.; Liu, B.; Jiang, L.; Zhu, D. Super-Hydrophobic Surfaces: From Natural to Artificial. Adv. Mater. 2002, 14, 1857-1860. [CrossRef]

12. Banerjee, D.; Mukherjee, S.; Chattopadhyay, K.K. Controlling the surface topology and hence the hydrophobicity of amorphous carbon thin films. Carbon 2010, 48, 1025-1031. [CrossRef]

13. Ostrovskaya, L.; Perevertailo, V.; Ralchenko, V.; Dementjev, A.; Loginova, O. Wettability and surface energy of oxidized and hydrogen plasma-treated diamond films. Diam. Relat. Mater. 2002, 11, 845-850. [CrossRef]

14. Piazza, F.; Morell, G. Wettability of hydrogenated tetrahedral amorphous carbon. Diam. Relat. Mater. 2009, 18, 43-50. [CrossRef]

15. Bismarck, A.; Brostow, W.; Chiu, R.; Hagg Lobland, H.E.; Ho, K.K.C. Effects of surface plasma treatment on tribology of thermoplastic polymers. Polym. Eng. Sci. 2008, 48, 1971-1976. [CrossRef]

16. Koidl, P.; Wild, C.; Dischler, B.; Wagner, J.; Ramsteiner, M. Plasma Deposition, Properties and Structure of Amorphous Hydrogenated Carbon Films. MSF 1991, 52-53, 41-70. [CrossRef]

17. Robertson, J. Diamond-like amorphous carbon. Mater. Sci. Eng. R Rep. 2002, 37, 129-281. [CrossRef]

18. Zhou, Y.; Wang, B.; Song, X.; Li, E.; Li, G.; Zhao, S.; Yan, H. Control over the wettability of amorphous carbon films in a large range from hydrophilicity to super-hydrophobicity. Appl. Surf. Sci. 2006, 253, 2690-2694. [CrossRef]

19. Schlebrowski, T.; Beucher, L.; Bazzi, H.; Hahn, B.; Wehner, S.; Fischer, C.B. Prediction of a-C:H layer failure on industrial relevant biopolymer polylactide acide (PLA) foils based on the sp2/sp3 ratio. Surf. Coat. Technol. 2019, 368, 79-87. [CrossRef]

20. Schlebrowski, T.; Beucher, L.; Bazzi, H.; Hahn, B.; Wehner, S.; Fischer, C.B. Changing Contents of Carbon Hybridizations in Amorphous Hydrogenated Carbon Layers $(\mathrm{a}-\mathrm{C}: \mathrm{H})$ on Sustainable Polyhydroxybutyrate (PHB) Exhibit a Significant Deterioration in Stability, Depending on Thickness. C 2019, 5, 52. [CrossRef]

21. Robertson, J. Plasma Deposition of Diamond-Like Carbon. Jpn. J. Appl. Phys. 2011, 50, 01AF01. [CrossRef]

22. Lee, S.-C.; Tai, F.-C.; Wei, C.-H. Correlation between sp2/sp3 Ratio or Hydrogen Content and Water Contact Angle in Hydrogenated DLC Film. Mater. Trans. 2007, 48, 2534-2538. [CrossRef] 
23. Schlebrowski, T.; Acharchi, H.; Hahn, B.; Wehner, S.; Fischer, C.B. Refinement of Sustainable Polybutylene Adipate Terephthalate (PBAT) with Amorphous Hydrogenated Carbon Films (a-C:H) Revealing Film Instabilities Influenced by a Thickness-Dependent Change of sp2/sp3 Ratio. Materials 2020, 13, 1077. [CrossRef]

24. Fischer, C.B.; Rohrbeck, M.; Wehner, S.; Richter, M.; Schmeißer, D. Interlayer formation of diamond-like carbon coatings on industrial polyethylene: Thickness dependent surface characterization by SEM, AFM and NEXAFS. Appl. Surf. Sci. 2013, 271, 381-389. [CrossRef]

25. Rohrbeck, M.; Körsten, S.; Fischer, C.B.; Wehner, S.; Kessler, B. Diamond-like carbon coating of a pure bioplastic foil. Thin Solid Film. 2013, 545, 558-563. [CrossRef]

26. Neyts, E.; Bogaerts, A.; Van de Sanden, M.C.M. Reaction mechanisms and thin a-C: H film growth from low energy hydrocarbon radicals. J. Phys. Conf. Ser. 2007, 86, 012020. [CrossRef]

27. Catena, A.; Kunze, M.R.; Agnello, S.; Gelardi, F.M.; Wehner, S.; Fischer, C.B. Amorphous hydrogenated carbon (a-C:H) depositions on polyoxymethylene: Substrate influence on the characteristics of the developing coatings. Surf. Coat. Technol. 2016, 307, 658-665. [CrossRef]

28. Schlebrowski, T.; Rouabeh, W.; Wehner, S.; Fischer, C.B. Specifying the interlayer turning point and dehydrogenation in a-C:H layers plasma deposited on high-density polyethylene with X-ray synchrotron techniques. Thin Solid Film. 2019, 691, 137617. [CrossRef]

29. Schlebrowski, T.; Lüber, H.; Beucher, L.; Fritz, M.; Benjillali, Y.; Bentaouit, M.; Hahn, B.; Wehner, S.; Fischer, C.B. Plasma Supported Deposition of Amorphous Hydrogenated Carbon (a-C:H) on Polyamide 6: Determining Interlayer Completion and Dehydrogenation Effects during Layer Growth. Polymers 2021, 13, 1886. [CrossRef] [PubMed]

30. Nefedov, A.; Wöll, C. Advanced Applications of NEXAFS Spectroscopy for Functionalized Surfaces. In Surface Science Techniques; Bracco, G., Holst, B., Eds.; Springer Berlin Heidelberg: Berlin/Heidelberg, Germany, 2013; pp. 277-303. ISBN 978-3-642-34242-4.

31. Fang, D.; He, F.; Xie, J.; Xue, L. Calibration of Binding Energy Positions with C1s for XPS Results. J. Wuhan Univ. Technol. Mat. Sci. Ed. 2020, 35, 711-718. [CrossRef]

32. Watts, B.; Thomsen, L.; Dastoor, P.C. Methods in carbon K-edge NEXAFS: Experiment and analysis. J. Electron. Spectrosc. Relat. Phenom. 2006, 151, 105-120. [CrossRef]

33. Schlebrowski, T.; Ouali, R.; Hahn, B.; Wehner, S.; Fischer, C.B. Comparing the Influence of Residual Stress on Composite Materials Made of Polyhydroxybutyrate (PHB) and Amorphous Hydrogenated Carbon (a-C:H) Layers: Differences Caused by Single Side and Full Substrate Film Attachment during Plasma Coating. Polymers 2021, 13, 184. [CrossRef]

34. Lacerda, R.G.; Marques, F.C. Hard hydrogenated carbon films with low stress. Appl. Phys. Lett. 1998, 73, 617-619. [CrossRef]

35. Marques, F.C.; Lacerda, R.G.; Odo, G.Y.; Lepienski, C.M. On the hardness of a-C:H films prepared by methane plasma decomposition. Thin Solid Film. 1998, 332, 113-117. [CrossRef]

36. Tai, F.C.; Lee, S.C.; Wei, C.H.; Tyan, S.L. Correlation between ID/G Ratio from Visible Raman Spectra and sp2/sp3 Ratio from XPS Spectra of Annealed Hydrogenated DLC Film. Mater. Trans. 2006, 47, 1847-1852. [CrossRef]

37. Solomon, J.L.; Madix, R.J.; Stöhr, J. Orientation and absolute coverage of benzene, aniline, and phenol on Ag(110) determined by NEXAFS and XPS. Surf. Sci. 1991, 255, 12-30. [CrossRef]

38. Dietrich, P.M.; Horlacher, T.; Girard-Lauriault, P.-L.; Gross, T.; Lippitz, A.; Min, H.; Wirth, T.; Castelli, R.; Seeberger, P.H.; Unger, W.E.S. Adlayers of dimannoside thiols on gold: Surface chemical analysis. Langmuir 2011, 27, 4808-4815. [CrossRef]

39. Stöhr, J. NEXAFS Spectroscopy; Springer: Berlin/Heidelberg, Germany, 1992; ISBN 978-3-662-02853-7.

40. Brüster, B.; Amozoqueño, C.; Grysan, P.; Peral, I.; Watts, B.; Raquez, J.-M.; Dubois, P.; Addiego, F. Resolving Inclusion Structure and Deformation Mechanisms in Polylactide Plasticized by Reactive Extrusion. Macromol. Mater. Eng. 2017, 302, 1700326. [CrossRef]

41. Díaz, J.; Anders, S.; Zhou, X.; Moler, E.J.; Kellar, S.A.; Hussain, Z. Analysis of the $\pi^{*}$ and $\sigma^{*}$ bands of the x-ray absorption spectrum of amorphous carbon. Phys. Rev. B 2001, 64, 125204. [CrossRef]

42. Dhez, O.; Ade, H.; Urquhart, S.G. Calibrated NEXAFS spectra of some common polymers. J. Electron Spectrosc. Relat. Phenom. 2003, 128, 85-96. [CrossRef]

43. Diaz, J.; Monteiro, O.R.; Hussain, Z. Structure of amorphous carbon from near-edge and extended x-ray absorption spectroscopy. Surf. Coat. Technol. 2007, 76, 094201. [CrossRef] 